\title{
Heat Capacities of Aqueous Ternary Mixtures of 2-Amino-2-Methyl-1, 3-Propanediol + Piperazine or Lithium Bromide
}

\author{
Rhedita Wanda Olivia, Rhoda B. Leron, and Meng-Hui Li
}

\begin{abstract}
In this work, we reported the molar heat capacities, $C_{P}$, of aqueous solutions of the sterically hindered amines 2-amino-2-methyl-1, 3-propanediol (AMPD), and its aqueous ternaries containing piperazine $(\mathrm{PZ})$ or lithium bromide $(\mathrm{LiBr})$. Measurements were performed in the temperature range 303.15 $\mathrm{K}$ to $353.15 \mathrm{~K}$ and atmospheric pressure by heat flow differential scanning calorimetry. The excess molar heat capacities, $C_{P}{ }^{E}$, of the binary solutions were determined, and the data were represented as function of temperature and composition using a Redlich-Kister-type equation. The $C_{P}$ of the ternary mixtures was correlated with temperature and amine concentration using the Sohnel and Novotny equation. Results showed that the calculated data agree very well with experimental $C_{P}$ values at average absolute deviation values of less than $0.2 \%$.
\end{abstract}

Index Terms-2-amino-2-methyl-1, 3-propanediol, molar heat capacity, redlich-kister equation, sohnel and novotny equation.

\section{INTRODUCTION}

Bulk removal of carbon dioxide from flue gas streams is commonly accomplished by amine-based chemical absorption. For such process, aqueous alkanolamine solutions are the most widely used absorbents, and of particular commercial importance are monoethanolamine (MEA), diethanolamine (DEA), and methyldiethanolamine (MDEA). MEA, a primary amine, and DEA, a secondary amine, are favorable due to their high reaction rates with $\mathrm{CO}_{2}$, which is due to the formation of stable carbamates. However, this limits the $\mathrm{CO}_{2}$ loading to $0.5-1.0 \mathrm{~mol}$ of $\mathrm{CO}_{2}$ per mol of amine, and leads to high energy requirement during amine regeneration. On the other hand, tertiary amines like MDEA can theoretically achieve high $\mathrm{CO}_{2}$ loading, which is due to the formation of bicarbonates (instead of carbamates), but their low $\mathrm{CO}_{2}$ absorption rate limits their use [1].

Sterically hindered amine is another type of amine absorbents, which gained interest in recent years. It is defined, based on molecular structure, as a primary amine in which the

Manuscript received August 1, 2013; revised October 1, 2013.

R. W. Olivia is with the Department of Chemical Engineering of Chung Yuan Christian University, Chungli, Taiwan (e-mail: rheditawanda@yahoo.com).

R. B. Leron is with the Mapua Institute of Technology, Manila, Philippines. She is currently conducting post-doctoral research studies at the Thermodynamics Research Laboratory at the Department of Chemical Engineering in Chung Yuan Christian University (e-mail: rbleron@mapua.edu.ph).

M. H. Li is with the Department of Chemical Engineering, and the current dean of the College of Engineering of Chung Yuan Christian University (e-mail: mhli@cycu.edu.tw). amino group is attached to a tertiary carbon or a secondary amine in which the amino group is attached to at least one secondary or tertiary carbon [2], [3]. Due to the hindrance produced by the bulky group adjacent to its amino group, a sterically hindered amine forms unstable carbamate with $\mathrm{CO}_{2}$. This carbamate hydrolyses to bicarbonate and free amine, and increases the theoretical $\mathrm{CO}_{2}$ loading to up to $1 \mathrm{~mol}$ of $\mathrm{CO}_{2}$ per mol of amine [2]. It has been reported that 2-amino-2-methyl-1-propanol (AMP), which is the most popular sterically hindered amine, has $\mathrm{CO}_{2}$ loading that is much higher than MEA, DEA, and TEA (triethanolamine) [4], [5]. The reaction mechanism of the absorption of $\mathrm{CO}_{2}$ in aqueous AMP solutions, as well as the kinetic constants, has also been extensively studied [6], [7]. A number of publications reported the thermophysical properties of the solvent at different ranges of concentrations and temperatures [7]-[10]. Furthermore, a number of empirical and theoretical models have been proposed to describe the absorption behavior of $\mathrm{CO}_{2}$ in aqueous AMP solutions, and to predict the solvent's physical and thermal properties. Other studies proposed the use of AMP in combination with other amines such as MEA, DEA, or MDEA or the activator piperazine (PZ) [11]-[14].

Other sterically hindered amines, which are suggested as potential absorbents for $\mathrm{CO}_{2}$ capture include 2-amino-2ethyl-1,3-propanediol (AEPD), 2-amino-2-hydroxy- methyl1,3-propanediol (AHPD), and 2-amino-2-methyl-1,3propanediol (AMPD). It was found that the loading capacities of these amines were higher than that of MEA [15]-[17]. For aqueous AMPD, Baek and Yoon [17] reported the solubility of $\mathrm{CO}_{2}$ in $10 \mathrm{wt} \%$ and $30 \mathrm{wt} \%$ aqueous solutions at $303 \mathrm{~K}, 313 \mathrm{~K}$, and $333 \mathrm{~K}$ and over $\mathrm{CO}_{2}$ partial pressures from $0.6 \mathrm{kPa}$ to $3064 \mathrm{kPa}$. They found that the solubility of $\mathrm{CO}_{2}$ in the $30 \mathrm{wt} \%$ AMPD solution at $40^{\circ} \mathrm{C}$ was similar to that in $30 \mathrm{wt} \%$ aqueous MDEA solution. They also proposed a modified Kent-Eisenberg model to predict the solubility behavior of $\mathrm{CO}_{2}$ in the solvent [18]. Bouhamara et al. [19] and Yoon et al. [20] studied the mechanism and kinetics of absorption of $\mathrm{CO}_{2}$ in aqueous AMPD solutions, and measured the kinetic constants. Other available data are density and viscosity of some aqueous AMPD solutions [21]. However, for these systems, thermal properties like heat capacity, which are required in the design of heat exchange equipment installed in absorption and stripping columns are not yet available in the literature.

In this work, we presented new data on the molar heat capacity, $C_{P}$, of aqueous AMPD solutions and their ternary mixtures containing $\mathrm{PZ}$, which is expected to improve the $\mathrm{CO}_{2}$ absorption rate of the amine [12], [22]. Moreover, the $C_{P}$ 
of aqueous ternary solutions of AMPD containing the salt $\mathrm{LiBr}$, which may lower the vapor pressure and molar heat capacity of aqueous amine solutions [23], [24], were also measured. The experimental data were used to calculate excess molar heat capacities, $C_{P}{ }^{E}$, of the binary solutions, and heat capacity differences, $C_{P}-C_{P a}$, of the ternary systems. We also aimed to present suitable correlations, which can be used to predict the heat capacities of the studied amine systems as function of temperature and concentration.

\section{EXPERIMENTAL SECTION}

\section{A. Chemicals}

2-amino-2-methyl-1, 3-propanediol (purity > $99 \mathrm{wt} \%$ ), piperazine (purity $>99 \mathrm{wt} \%$ ), and lithium bromide (purity $>$ 99wt\%) were purchased from Acros Organics. They were used in the experiments without further purification. High-purity distilled water (resistivity $=18.3 \mathrm{~m} \Omega$ ), which was deionized in a Barnstead Thermolyne (model Easy Pure 1052) water purification system was used in the experiments. The aqueous samples were prepared by mass using a digital balance (Mettler Toledo model AL204) with accuracy $\pm 1 \times$ $10^{-4} \mathrm{~g}$.

\section{B. Heat Capacity Measurement}

The measurement of heat capacity was performed using TA Instruments heat flow differential scanning calorimeter (DSC) (model DSC-2010). The DSC was equipped with a thermal analysis controller. The experimental setup and method (sapphire method) and the validation tests (using water and dipropylene glycol) were discussed in detail in our previous works [9], [25], [26].

For each measurement, 10-15 $\mathrm{mg}$ of the sample, encapsulated in an alodined aluminum hermetic pan, was used. The obtained differential heat flow curve of the sample was compared with that of standard sapphire (with both curves blank corrected). The purge gas used was nitrogen (purity > 99.9995\%) at a flow rate of $40 \mathrm{~mL} / \mathrm{min}$. The repeatability of the temperature measurement was $\pm 0.1 \mathrm{~K}$. Periodic calibration (using indium as calibrant) of the DSC was also conducted to ensure the accuracy of the measurements. $C_{P}$ measurements were done in three to five replicates. The overall uncertainty of the measurements was estimated to be $\pm 2 \%$.

\section{RESULTS AND DISCUSSION}

The molar heat capacities of aqueous binary solutions of AMPD at concentrations $\left(x_{1}=0.10,0.15,0.20,0.25\right.$, and 0.3$)$ were measured in the temperature range $303.15 K$ to $353.15 K$. The experimental data are given in Table I. The range of concentrations used was chosen based on the solubility of AMPD in water. Also, due to scarcity of data available on the heat capacity of pure AMPD, we also measured the latter in the temperature up to which before the sample experienced phase change. As indicated in Table I, the $C_{P}$ of the samples increased slightly as the temperature increased. This behavior is expected since higher degrees of freedom are available in the sample at higher temperatures. It is also noticeable that the $C_{P}$ of the solutions increased with increasing amine concentration. Such can be attributed to the higher molecular weight of the amine compared to water; hence, the greater number of translational, vibrational, and rotational energy storage modes in the former.

TABLE I: MOLAR HEAT CAPACITIES OF AQUEOUS AMPD SOLUTIONS

\begin{tabular}{lllllll}
\hline \multicolumn{7}{c}{ Heat capacity, $C_{P}\left(J \cdot \mathrm{mol}^{-1} \cdot K^{-1}\right)$} \\
\hline$T(K)$ & $x_{1}=0.10$ & $x_{1}=0.15$ & $x_{1}=0.20$ & $x_{1}=0.25$ & $x_{1}=0.30$ & $x_{1}=1$ \\
\hline 303.2 & 95.6 & 106.9 & 116.0 & 125.2 & 134.4 & 204. \\
308.2 & 96.2 & 107.7 & 117.1 & 126.6 & 135.9 & 214. \\
313.2 & 96.4 & 108.2 & 117.8 & 127.5 & 137.0 & 226. \\
318.2 & 96.4 & 108.5 & 118.4 & 128.4 & 138.1 & 242. \\
323.2 & 96.6 & 109.0 & 119.2 & 129.5 & 139.2 & \\
328.2 & 96.7 & 109.3 & 119.9 & 130.3 & 140.3 & \\
333.2 & 96.9 & 109.7 & 120.6 & 131.4 & 141.5 & \\
338.2 & 97.1 & 110.3 & 121.5 & 132.6 & 142.9 & \\
343.2 & 97.2 & 110.7 & 122.1 & 133.6 & 144.0 & \\
348.2 & 97.5 & 111.2 & 123.0 & 134.7 & 145.4 & \\
353.2 & 97.8 & 111.8 & 123.8 & 135.8 & 146.9 & \\
\hline \hline
\end{tabular}

For the purpose of representing the $C_{P}$ of pure AMPD as function of temperature, we used a simple linear relation, such that

$$
C_{P}\left(J \cdot \mathrm{mol}^{-1} \cdot K^{-1}\right)=a_{1}+a_{2} T
$$

where $T$ is the temperature and $a_{1}, a_{2}$ are adjustable parameters whose values were obtained, by a least squares fit, to be -565.36 and 2.53 , respectively. The absolute average deviation (AAD) between the experimental and calculated data from (1) was $0.7 \%$.

The excess molar heat capacities, $C_{P}{ }^{E}$, of the aqueous binary solutions were obtained. By definition $C_{P}{ }^{E}$ is the difference between the heat capacity of the solution and the summation of the pure components contribution

$$
C_{P}{ }^{E}\left(J \cdot \mathrm{mol}^{-1} \cdot K^{-1}\right)=C_{P}-\sum_{i} x_{i} C_{P, i}
$$

where $x_{i}$ and $C_{P, i}$ are the mole fraction and molar heat capacity of component $i$, respectively. Then, a Redlich-Kister-type equation was applied to correlate $C_{P}{ }^{E}$ with temperature and composition (in mole fraction). The equation was in the form:

$$
C_{P}{ }^{E}\left(J \cdot \mathrm{mol}^{-1} \cdot K^{-1}\right)=x_{1} x_{2} \sum_{j=1}^{N} B_{i}\left(x_{1}-x_{2}\right)^{j-1}
$$

here, $B_{j}$ 's are pair-parameters, which were assumed temperature-dependent according to (4).

$$
B_{j}=b_{j, 0}+b_{j, 1} T
$$

where $b_{j, 0}$ and $b_{j, 1}$ are adjustable parameters obtained by fitting (3) and (4) using the experimental data. The calculated $C_{P}$ and $C_{P}{ }^{E}$ values are shown along with the experimental data in Fig. 1 and Fig. 2, respectively, whereas the obtained 
parameters and AAD are presented in Table II. The figures clearly show that the two sets of data are in good agreement, which is upheld by the low values of AADs for both $C_{P}$ $(0.1 \%)$ and $C_{P}{ }^{E}(3.4 \%)$. Fig. 2 also shows negative temperature dependence of the $C_{P}{ }^{E}$, that is $C_{P}{ }^{E}$ decreased with increasing temperature. At temperature higher than 343 $K$, the $C_{P}{ }^{E}$ were also found negative whereas at lower temperature, the values were positive for the whole range of AMPD concentrations. This may be an indication of the weakening of the hydrogen bond interactions in the liquid at higher temperatures.

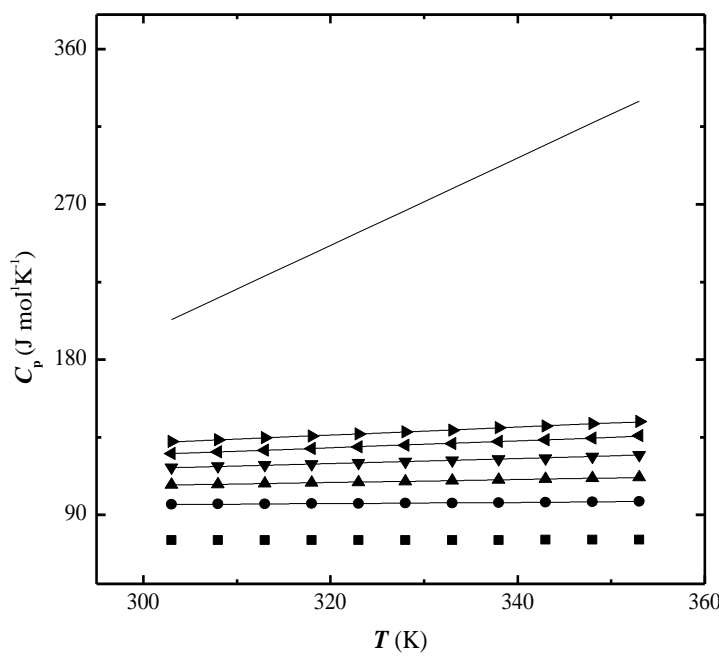

Fig. 1. Molar heat capacity of AMPD (1) $+\mathrm{H}_{2} \mathrm{O}$ (2) systems. $\mathbf{\square}, \mathrm{H}_{2} \mathrm{O}$ by Osborne et al. [27]; $\bigcirc, x_{1}=0.10 ; \triangle, x_{1}=0.15 ; \nabla, x_{1}=0.20 ; \triangleleft, x_{1}=0.25 ; \triangleright$, $x_{1}=0.30 ; \bigcirc, x_{1}=1 ;$ line, calculated.

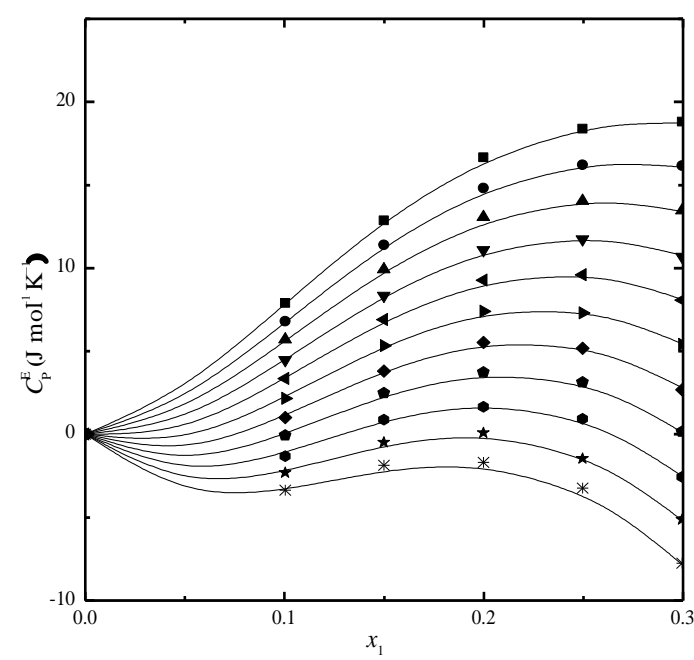

Fig. 2. Excess molar heat capacity of AMPD (1) $+\mathrm{H}_{2} \mathrm{O}$ (2) systems. $\mathbf{\square}, 303.15 K ; \boldsymbol{\bullet}, 308.15 K ; \boldsymbol{\Delta}, 313.15 K ; \boldsymbol{\nabla}, 318.15 K ; \mathbf{4}, 323.15 K$; $328.15 K, \bullet, 333.15 K ; \bullet, 338.15 K ; \bullet, 343.15 K ; \star, 348.15 K ; *$ * 353.15 $\mathrm{K}$, line, calculated by the Redlich-Kister-type equation.

TABLE II: PARAMETERS OF THE REDLICH-KISTER EQUATION FOR THE $C_{P}$ OF THE BINARY SYSTEMS

\begin{tabular}{|c|c|c|c|c|c|}
\hline \multirow{2}{*}{$j$} & \multicolumn{2}{|c|}{ Parameters } & \multirow{2}{*}{$\begin{array}{c}\text { No. of data } \\
\text { points }\end{array}$} & \multicolumn{2}{|c|}{$\operatorname{AAD}(\%)$} \\
\hline & $b_{j, 0}$ & $b_{j, 1}$ & & $C_{P}{ }^{E}$ & $C_{P}$ \\
\hline 1 & 1718.3 & -5.31 & & & \\
\hline 2 & 3906.3 & -11.86 & 55 & 3.4 & 0.1 \\
\hline 3 & 5250.0 & -14.18 & & & \\
\hline
\end{tabular}

TABLE III: MOLAR HEAT CAPACITIES OF PZ (1) + AMPD (2) + $\mathrm{H}_{2} \mathrm{O}$ (3) SOLUTIONS

\begin{tabular}{cccccc}
\hline \hline$T(K)$ & \multicolumn{5}{c}{ Heat capacity, $C_{P}\left(J \cdot \mathrm{mol}^{-1} \cdot K^{-1}\right)$} \\
\cline { 2 - 6 }$(22 / 26 / 52)$ & $(26 / 31 / 43)$ & $(29 / 35 / 36)$ & $(31 / 38 / 31)$ & $(34 / 41 / 25)$ \\
& $m_{1}=3.220$ & $m_{1}=4.017$ & $m_{1}=4.695$ & $m_{1}=5.293$ & $m_{1}=5.813$ \\
\hline 303.2 & 91.5 & 103.0 & 113.9 & 122.9 & 131.3 \\
308.2 & 92.3 & 104.4 & 115.7 & 125.0 & 133.4 \\
313.2 & 93.1 & 105.8 & 117.4 & 127.1 & 135.6 \\
318.2 & 93.4 & 107.2 & 119.1 & 129.3 & 137.6 \\
323.2 & 94.2 & 108.6 & 120.9 & 131.5 & 139.6 \\
328.2 & 95.0 & 110.0 & 122.8 & 133.7 & 141.7 \\
333.2 & 95.8 & 111.4 & 124.5 & 135.8 & 143.8 \\
338.2 & 96.6 & 112.9 & 126.3 & 138.0 & 145.9 \\
343.2 & 97.4 & 114.3 & 128.2 & 140.3 & 147.9 \\
348.2 & 98.3 & 115.7 & 130.0 & 142.4 & 150.1 \\
353.2 & 99.0 & 117.1 & 131.8 & 144.7 & 152.1 \\
\hline \hline
\end{tabular}

TABLE IV: MOLAR HEAT CAPACITIES OF LiBR (1) + AMPD (2) + $\mathrm{H}_{2} \mathrm{O}$ (3) SOLUTIONS

\begin{tabular}{|c|c|c|c|c|c|}
\hline \multirow{4}{*}{$T(K)$} & \multicolumn{5}{|c|}{ Heat capacity, $C_{P}\left(J \cdot \mathrm{mol}^{-1} \cdot K^{-1}\right)$} \\
\hline & \multicolumn{5}{|c|}{$\left(\mathrm{LiBr} w t \% / \mathrm{AMPD} w t \% / \mathrm{H}_{2} \mathrm{O} w t \%\right)$} \\
\hline & $(22 / 53 / 25)$ & $(27 / 43 / 30)$ & $(30 / 36 / 34)$ & $(32 / 31 / 37)$ & $(36 / 22 / 42)$ \\
\hline & $m_{1}=3.219$ & $m_{1}=4.158$ & $m_{1}=4.871$ & $m_{1}=5.398$ & $m_{1}=6.546$ \\
\hline 303.2 & 78.8 & 87.7 & 93.6 & 102.9 & 116.7 \\
\hline 308.2 & 79.1 & 88.2 & 94.2 & 103.8 & 117.9 \\
\hline 313.2 & 79.5 & 88.6 & 94.8 & 104.6 & 119.1 \\
\hline 318.2 & 79.9 & 89.1 & 95.4 & 105.4 & 120.3 \\
\hline 323.2 & 80.2 & 89.6 & 96.0 & 106.2 & 121.5 \\
\hline 328.2 & 80.6 & 90.1 & 96.6 & 107.1 & 122.7 \\
\hline 333.2 & 81.0 & 90.6 & 97.3 & 107.9 & 124.0 \\
\hline 338.2 & 81.4 & 91.1 & 97.9 & 108.8 & 125.2 \\
\hline 343.2 & 81.8 & 91.6 & 98.6 & 109.6 & 126.4 \\
\hline 348.2 & 82.2 & 92.1 & 99.2 & 110.5 & 127.6 \\
\hline 353.2 & 82.6 & 92.6 & 99.8 & 111.3 & 128.9 \\
\hline
\end{tabular}

Table III and Table IV present the experimental $C_{P}$ of the aqueous ternary systems at $303.15 K$ to $353.15 K$. The ranges of concentrations (for AMPD and PZ or $\mathrm{LiBr}$ ), which were chosen were limited by the solubility of the amines and the salt in water. It is indicated in Table III that the $C_{P}$ of PZ (1) + AMPD (2) $+\mathrm{H}_{2} \mathrm{O}$ (3) solutions increased with increasing increased as the concentration of $\mathrm{PZ}$ in the solution (in molality) increased. For each sample, the heat capacity temperature and total amine concentration. The $C_{P}$ also difference, $C_{P}-C_{P a}$, was also obtained where $C_{P a}$ is the heat capacity of the PZ- or salt-free solution calculated using (2) to (4) along with the parameters listed in Table I. As shown in 
Fig. 3 (a), the $C_{P}-C_{P a}$ of all studied PZ (1) + AMPD (2) + $\mathrm{H}_{2} \mathrm{O}$ (3) systems were positive, which suggests that the addition of $\mathrm{PZ}$ to aqueous binary AMPD solutions tends to increase the systems' $C_{P}$. On the other hand, the $C_{P}$ of $\operatorname{LiBr}(1)$ + AMPD (2) $+\mathrm{H}_{2} \mathrm{O}$ (3) solutions increased with increasing amount of the salt in the solution. The values of the $C_{P}-C_{P a}$ are plotted as function of salt concentration $\left(m_{1}\right)$ in Fig. 3 (b). As shown, negative $C_{P}-C_{P a}$ were obtained, which suggests that the addition of $\mathrm{LiBr}$ tends to decrease the heat capacity of the corresponding aqueous AMPD solutions.
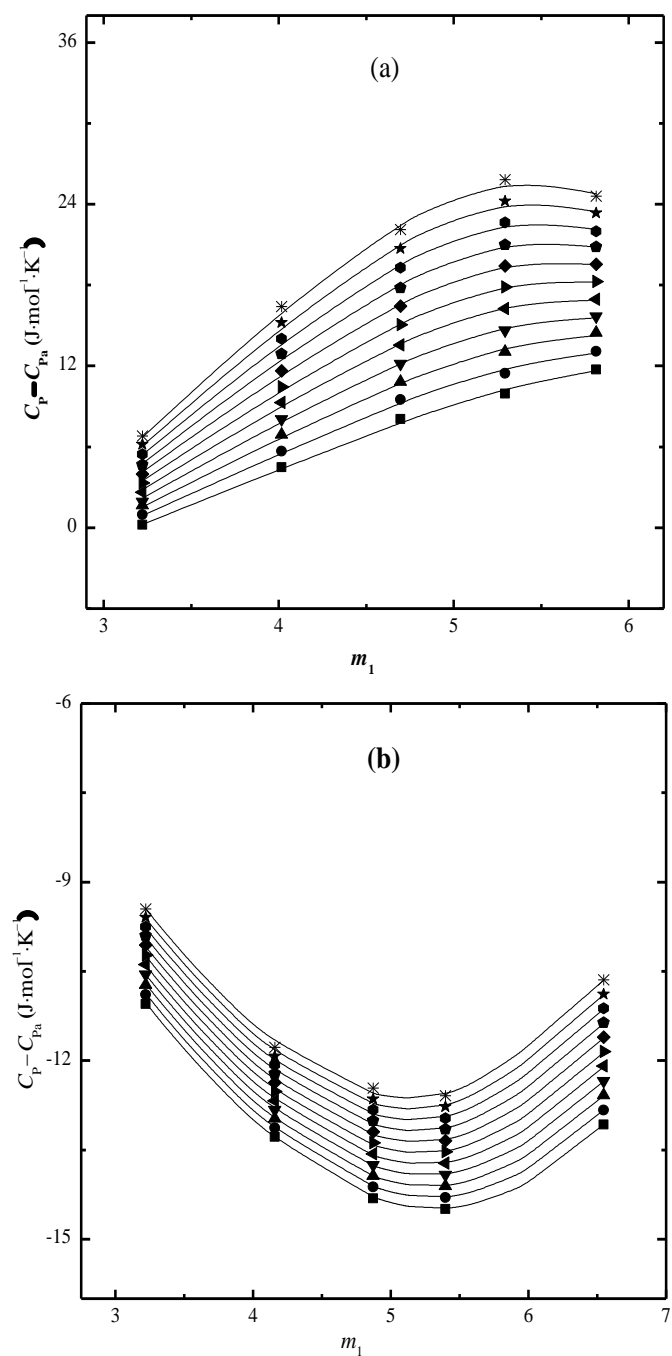

Fig. 3. Molar heat capacity difference of (a) $\mathrm{PZ}+\mathrm{AMPD}+\mathrm{H}_{2} \mathrm{O} ;$ (b) $\mathrm{LiBr}+$ $\mathrm{AMPD}+\mathrm{H}_{2} \mathrm{O}: \mathbf{\square}, 303.15 K ; \bullet, 308.15 K ; \boldsymbol{\Delta}, 313.15 K ; \boldsymbol{\nabla}, 318.15 K ; \mathbf{4}$, $323.15 K ; \bullet, 328.15 K ; \bullet, 333.15 K ; \bullet, 338.15 K ; \bullet, 343.15 K ; \star, 348.15$ $K$; $*$, $353.15 K$; line, calculated by modified Sohnel and Novotny equation.

TABLE V: PARAMETERS OF THE SOHNEL AND NOVOTNY EQUATION FOR THE $C_{P}$ OF THE TERNARY SYSTEMS

\begin{tabular}{|c|c|c|c|c|c|c|}
\hline \multirow[b]{2}{*}{ System } & \multirow[b]{2}{*}{$j$} & \multicolumn{2}{|c|}{ parameters } & \multirow{2}{*}{$\begin{array}{l}\text { No. of } \\
\text { data } \\
\text { points }\end{array}$} & \multicolumn{2}{|c|}{$\operatorname{AAD}(\%)$} \\
\hline & & $d_{\mathrm{i}, 0}$ & $d_{\mathrm{i}, 1}$ & & $\begin{array}{c}C_{P}- \\
C_{P a} \\
\end{array}$ & $C_{P}$ \\
\hline \multirow{3}{*}{$\begin{array}{c}\mathrm{PZ}(1)+ \\
\mathrm{AMPD}(2)+ \\
\mathrm{H}_{2} \mathrm{O}(3)\end{array}$} & 1 & 49.66 & -0.1898 & \multirow{3}{*}{55} & \multirow{3}{*}{2.0} & \multirow{3}{*}{0.14} \\
\hline & 2 & -29.92 & 0.1100 & & & \\
\hline & 3 & 3.33 & -0.0120 & & & \\
\hline \multirow{3}{*}{$\begin{array}{c}\mathrm{LiBr}(1)+ \\
\operatorname{AMPD}(2)+ \\
\mathrm{H}_{2} \mathrm{O}(3)\end{array}$} & 1 & -11.15 & 0.0265 & \multirow{3}{*}{55} & \multirow{3}{*}{0.2} & \multirow{3}{*}{0.02} \\
\hline & 2 & 1.93 & -0.0076 & & & \\
\hline & 3 & -0.14 & 0.0007 & & & \\
\hline
\end{tabular}

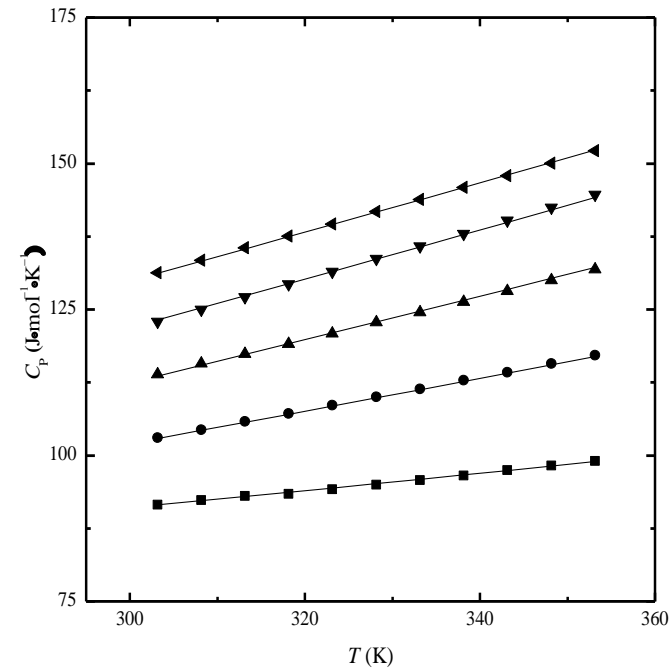

Fig. 4. Molar heat capacity of $\mathrm{PZ}+\mathrm{AMPD}+\mathrm{H}_{2} \mathrm{O}$ systems: $\mathbf{\square}, 21.71 w t \%$ $\mathrm{PZ} / 26.48 w t \%$ AMPD/61.25 wt\% $\mathrm{H}_{2} \mathrm{O} ;-25.71 w t \% \mathrm{PZ} / 31.35 w t \%$ AMPD/42.94 wt\% $\mathrm{H}_{2} \mathrm{O} ; \boldsymbol{\Delta}, 28.79 w t \%$ PZ/35.11 wt\% AMPD/36.10 wt\% $\mathrm{H}_{2} \mathrm{O} ; \boldsymbol{\nabla}, 31.31 w t \%$ PZ/38.18 wt\% AMPD/30.51wt\% $\mathrm{H}_{2} \mathrm{O} ; 33.37 w t \%$ $\mathrm{PZ} / 40.69 w t \%$ AMPD/25.94 wt\% $\mathrm{H}_{2} \mathrm{O}$; lines, calculated by the modified Sohnel and Novotny equation.

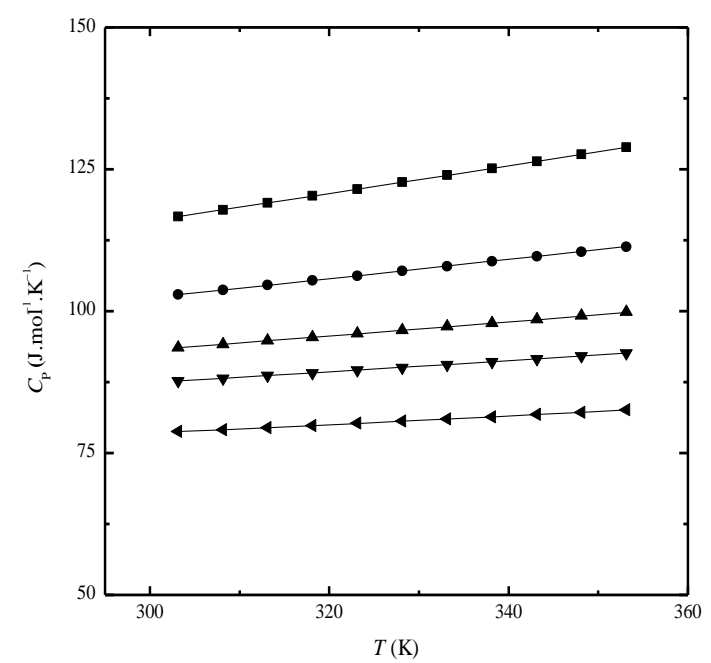

Fig. 5. Molar heat capacity of $\mathrm{LiBr}+\mathrm{AMPD}+\mathrm{H}_{2} \mathrm{O}$ systems: $\mathbf{\square}, 36.25 w t \%$ $\mathrm{LiBr} / 21.92 w t \%$ AMPD/41.83 wt\% $\mathrm{H}_{2} \mathrm{O} ;-31.92 w t \% \mathrm{LiBr} / 31.24 w t \%$ AMPD/36.84 wt\% $\mathrm{H}_{2} \mathrm{O} ; \boldsymbol{\Delta}, 29.73 w t \% \mathrm{LiBr} / 35.96 w t \%$ AMPD/34.31 wt\% $\mathrm{H}_{2} \mathrm{O} ; \boldsymbol{\nabla}, 26.53 w t \% \mathrm{LiBr} / 42.85 w t \%$ AMPD/30.62 wt\% $\mathrm{H}_{2} \mathrm{O} ;<, 21.85 w t \%$ $\mathrm{LiBr} / 52.93 w t \%$ AMPD/25.22 $w t \% \mathrm{H}_{2} \mathrm{O}$; lines, calculated by the modified Sohnel and Novotny equation.

An empirical model proposed by Sohnel and Novotny [28] was applied to represent the dependence of the $C_{P}$ of the aqueous ternary systems on temperature and solute $(\mathrm{PZ}$ or $\mathrm{LiBr}$ and AMPD) concentration. The model was modified, and the following form was used:

$$
C_{P}\left(J \cdot \mathrm{mol}^{-1} \cdot K^{-1}\right)=C_{P a}+D_{1}\left(m_{1}\right)+D_{2}\left(m_{1}\right)^{2}+D_{3}\left(m_{1}\right)^{3}
$$

where $C_{P a}$ is the molar heat capacity of the $\mathrm{PZ}$ or salt-free aqueous solution (AMPD $\left.+\mathrm{H}_{2} \mathrm{O}\right), m_{1}$ is the molality of the solution (in terms of mol PZ or $\mathrm{LiBr}$ per $\mathrm{kg}$ AMPD $+\mathrm{H}_{2} \mathrm{O}$ ), and $D_{j}$ 's are pair-parameters, which were assumed to be dependent on temperature:

$$
D_{j}=d_{j, 0}+d_{j, 1} T
$$


where $d_{j, 0}$ and $d_{j, 1}$ are adjustable parameters (Table $\mathrm{V}$ ) obtained by non linear least squares fit. In (5), the values of $C_{P a}$ were calculated by the Redlich-Kister-type equation, which has been presented earlier, using the empirical constants listed in Table II. The calculated values of $C_{P}-C_{P a}$ are presented as lines in Fig. 3 where they are to be in reasonable agreement with the experimental data. Also, the $C_{\mathrm{P}}$ values for $\mathrm{PZ}(1)+\mathrm{AMPD}(2)+\mathrm{H}_{2} \mathrm{O}$ (3) and $\mathrm{LiBr}(1)+$ AMPD (2) $+\mathrm{H}_{2} \mathrm{O}$ (3) calculated from (5) and (6) were plotted along with the experimental data in Fig. 4 and Fig. 5, respectively. It is suggested by good fit of the lines that the applied modified Sohnel and Novotny equation satisfactorily model the behavior of the $C_{P}$ as function of temperature and concentration. Thus, the model can be used in process engineering to yield accurate predictions of the $C_{P}$ the studied amine systems.

\section{ACKNOWLEDGMENT}

This research was supported by a grant, NSC 101-3113-E-007-005, from the National Science Council of the Republic of China.

\section{REFERENCES}

[1] A. L. Kohl and R. B. Nielsen, Gas Purification, $5^{\text {th }}$ ed. Houston: Gulf Publishing Company, 1997.

[2] G. Sartori and D. W. Savage, "Sterically hindered amines for $\mathrm{CO}_{2}$ removal from gases," Ind. Eng. Chem. Fundam., vol. 22, pp. 239-249, 1983.

[3] F. Bougie and M. C. Iliuta, "Sterically hindered amine-based absorbents for the removal of $\mathrm{CO}_{2}$ from gas streams," J. Chem. Eng. Data, vol. 57, pp. 635-669, 2012

[4] B. E. Roberts and A. E. Mather. "Solubility of $\mathrm{CO}_{2}$ and $\mathrm{H}_{2} \mathrm{~S}$ in a hindered amine solution," Chem. Eng. Commun., vol. 64, pp. 105-111, 1988.

[5] T. T. Teng and A. E. Mather, "Solubility of carbon dioxide in an AMP solution," J. Chem. Eng. Data, vol. 35, pp. 410-411, 1990.

[6] A. K. Saha and S. S. Bandyopadhyay. "Kinetics of absorption of $\mathrm{CO}_{2}$ into aqueous solutions of 2-amino-methyl-1-propanol," Chem. Eng. Sci., vol. 50, pp. 3587-3598, 1995.

[7] S. M. Yih and K. P. Shen, "Kinetics of carbon dioxide reaction with sterically hindered 2-amino-2-methyl-1-propanol aqueous solutions," Ind. Eng. Chem. Res., vol. 27, pp. 2237-2241, 1988.

[8] M.-H. Li and Y.-C. Lie, "Densities and viscosities of solutions of monoethanolamine $+\mathrm{N}$-methyldiethanolamine + water and monoethanolamine + 2-amino-2-methyl-1-propanol + water," J. Chem. Eng. Data, vol. 39, pp. 444-447, 1994.

[9] L.-F. Chiu, H.-F. Liu, and M.-H. Li, "Heat capacity of alkanolamines by differential scanning calorimetry," J. Chem. Eng. Data, vol. 44, pp. 631-636, 1999.

[10] L.-F. Chiu and M.-H. Li, "Heat capacity of alkanolamine aqueous solutions," J. Chem. Eng. Data, vol. 44, pp. 1396-1401, 1999.

[11] B. P. Mandal, A. K. Biswas, and S. S. Bandyopadhyay, "Absorption of carbon dioxide into aqueous blends of 2-amino-2-methyl-1-propanol and diethanolamine," Chem. Eng. Sci., vol. 58, pp. 4137-4144, 2003.

[12] D. J. Seo and W. H. Hong, "Effect of piperazine on the kinetics of carbon dioxide with aqueous solutions of 2-amino-2-methyl-1propanol," Ind. Eng. Chem. Research, vol. 39, pp. 2062-2067, 1999.

[13] J. Xiao, C.-W. Li, and M.-H. Li, "Kinetics of absorption of carbon dioxide into aqueous solutions of 2-amino-2-methyl-1-propanol + monoethanolamine," Chem. Eng. Sci., vol. 55, pp. 161-175, 1998.

[14] M.-H. Li and B.-C. Chang, "Solubilities of carbon dioxide in water + monoethanolamine + 2-amino-2-methyl-1-propanol," J. Chem. Eng. Data, vol. 39, pp. 448-452, 1994.

[15] J.-Y. Park, S. J. Yoon, H. Lee, J.-H. Yoon, J.-G. Shim, J. K. Lee, B.-Y. Min, and H.-M. Eum, "Density, viscosity, and solubility of $\mathrm{CO}_{2}$ in aqueous solutions of 2-amino-2-hydroxymethyl-1, 3-propanediol," $J$. Chem. Eng. Data, vol. 47, pp. 970-973, 2002.
[16] J.-Y. Park, S. J. Yoon, H. Lee, J.-H. Yoon, J.-G. Shim, J. K. Lee, B.-Y. Minb, H.-M. Eumb, and M. C. Kangc, "Solubility of carbon dioxide in aqueous solutions of 2-amino-2-ethyl-1,3- propanediol," Fluid Phase Equilib., vol. 202, pp. 359-366, 2002

[17] J. I. Baek and J. H. Yoon. "Solubility of carbon dioxide in aqueous solutions of 2-amino-2-methyl-1, 3-propanediol," J. Chem. Eng. Data, vol. 43, pp. 635-637, Jul-Aug 1998.

[18] J.-I. Baek, J.-H. Yoon, and H.-M. Eum, "Prediction of equilibrium solubility of carbon dioxide in aqueous 2-amino-2-methyl-1, 3propanediol solutions," Korean J. Chem. Eng., vol. 17, pp. 484-487, 2000.

[19] W. Bouhamra, O. Bavbek, and E. Alper, "Reaction mechanism and kinetics of aqueous solutions of 2-amino-2-methyl-1, 3-propandiol and carbon dioxide," Chem. Eng. J., vol. 73, pp. 67-70, 1999.

[20] J.-H. Yoon, J.-I. Baek, Y. Yamamoto, T. Komai, and T. Kawamura, "Kinetics of removal of carbon dioxide by aqueous 2-amino2-methyl-1,3-propanediol," Chem. Eng. Sci., vol. 58, pp. 5229-5237, 2003.

[21] J. I. Baek, J. H. Yoon, and H. M. Eum, "Physical and thermodynamic properties of aqueous 2-amino-2-methyl-1, 3-propanediol solutions," Int. J. Thermophys., vol. 21, pp. 1175-1184, 2000.

[22] A. Samanta and S. S. Bandyopadhyay, "Density and viscosity of aqueous solutions of piperazine and (2-amino-2-methyl-1-propanol + piperazine) from 298 to 333 K," J. Chem. Eng. Data, vol. 51, pp. 467-470, 2006.

[23] C.-Y. Tsai, A. N. Soriano, and M.-H. Li, "Vapour pressures, densities, and viscosities of the aqueous solutions containing (triethylene glycol or propylene glycol) and ( $\mathrm{LiCl}$ or $\mathrm{LiBr}), " J$. Chem. Thermodyn., vol. 41, pp. 623-631, 2009.

[24] M. Randall and F. D. Rossini, "Heat capacities in aqueous salt solutions," J. Am. Chem. Soc., vol. 51, pp. 323-345, 1929.

[25] R. B. Leron and M.-H. Li, "Molar heat capacities of choline chloride-based deep eutectic solvents and their binary mixtures with water," Thermochim. Acta, vol. 530, pp. 52-57, 2012.

[26] Y.-C. Lu, A. R. Caparanga, R. B. Leron, and M.-H. Li, "Molar heat capacity of several aqueous solutions of $\mathrm{n}$-[tris(hydroxymethyl)methyl-3-amino]propanesulfonic acid (TAPS) + glycol," Thermochim Acta, vol. 540, pp. 69-73, 2012.

[27] N. S. Osborne, H. F. Stimson, and D. C. Ginnings, J. Res. Nat. Bur. Stand., vol. 23, pp. 197-260, 1939.

[28] O. Söhnel and P. Novotný, Densities of Aqueous Solutions of Inorganic Substances, ed. Amsterdam, Netherlands: Elsevier Science, 1985.

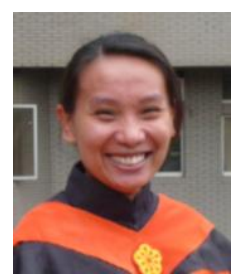

Rhedita Wanda Olivia was born in Malang, Indonesia in 1982. She graduated with a B.S. degree in chemical engineering from Institut Teknologi Sepuluh Nopember, Surabaya, Indonesia in 2001. She received her M.S. degree in chemical engineering at Chung Yuan Christian University, Chung Li, Taiwan in July 2013. Her major research is on the heat capacities of sterically hindered amines.

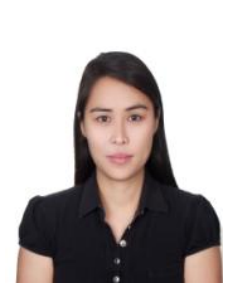

Rhoda B. Leron obtained her B.S. degree in chemical engineering at the Mapua Institute of Technology, Manila, Philippines in 2000. She earned her M.S. degree in environmental engineering from the same institution in 2004. In September 2012, she received her Ph.D. degree in chemical engineering from Chung Yuan Christian University, Chung Li, Taiwan. She is currently an associate professor at the Mapua Institute of Technology, and a postdoctoral research associate at Chung Yuan Christian University. Her research focuses on solubility and thermophysical properties measurements of deep eutectic solvents and advanced amine absorbents for $\mathrm{CO}_{2}$ capture.

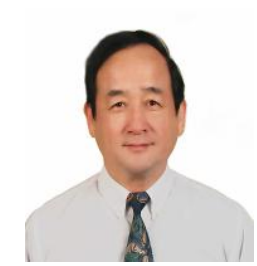

Meng-Hui Li received his B.S. degree in chemica engineering from Tunghai University, Tainan, Taiwan in 1976. He obtained his M.S./Ph.D. degrees in chemical engineering at the University of Oklahoma, U.S.A. in 1981 and 1984. He worked as a postdoctoral research associate at the University of OKlahoma from 1984-1987. At present, he is a professor at the Department of Chemical Engineering and the Dean of the College of Engineering of Chung Yuan Christian University. For more than 20 years, he has been working on carbon dioxide absorption in advanced solvents, amines, ionic liquids, deep eutectic solvents, etc. He published more than 100 papers in international SCI-abstracted journals. 